\title{
Physical and Chemical Studies of Some Short Grain and Medium Slender Aromatic Rice (Oryza sativa L.)
}

\author{
Dharmadew Chauhan ${ }^{1 *}$, Mukesh Mohan ${ }^{1}$, Pawan Kumar Goutam², \\ Dipak Kumar ${ }^{1}$ and Ajay Sonkar ${ }^{1}$ \\ ${ }^{1}$ Department of Agricultural Biochemistry, ${ }^{2}$ Department of Crop Physiology, College of \\ Agriculture, College of Agriculture, Chandra Shekhar Azad University of Agriculture and \\ Technology, Kanpur, 208002, Uttar Pradesh, India \\ *Corresponding author
}

\section{Keywords}

Aromatic rice, Short \& medium slender, Genotypes, Head rice recovery, Seed length, Seed breadth, L/B ratio, Alkali spreading value, Amylose content

Article Info

Accepted: 17 December 2018 Available Online: 10 January 2019

\section{A B S T R A C T}

The laboratory experiments were conducted in university lab entitled "Physical and chemical studies of some Short grain and Medium slender aromatic rice (Oryza sativa L.)" on the basis of the results obtained from the present study under the investigation of head rice recovery, grain length, grain breadth, length breadth ratio, alkali spreading value and amylose content are concluded as the head rice recovery ranged from 51.86-64.70 per cent. Data exhibited that maximum head rice recovery per cent was obtained $64.70 \%$ in R-3719 followed by R-3715, i.e., 63.79 per cent and minimum 51.86 per cent in Kalmunhi followed by R-3734 i.e., 54.51 per cent. The seed length varied from 4.96-7.26 mm. The maximum seed length was found $7.26 \mathrm{~mm}$ in R-3738, followed by R-3728 i.e., 7.24 and minimum for R-3715, i.e. $4.96 \mathrm{~mm}$, followed by R-3730 i.e., $5.36 \mathrm{~mm}$. The seed breadth, varied from 1.63-1.95 mm. The maximum seed breadth was found $1.95 \mathrm{~mm}$ in R-3746, followed by R-3724 i.e., 1.93 and minimum for R-3738, i.e. $1.63 \mathrm{~mm}$, followed by R-3747 i.e., $1.65 \mathrm{~mm}$. The length breadth ratio was ranged from 1.70-3.70 mm. Maximum L: B ratio was recorded with R-2804 i.e., $3.70 \mathrm{~mm}$. followed by Kala Namak i.e., $3.68 \mathrm{~mm}$ and minimum length breadth ratio are found in R-3720 i.e., $1.70 \mathrm{~mm}$. followed by R-3737 i.e., $1.79 \mathrm{~mm}$. The Alkali spreading value was ranged from $360 \times 500-600 \times 466$, respectively. The maximum alkali spreading value were obtained in R-3738 i.e., $600 \times 466$, respectively, followed by R-3722 and R-2802 i.e., $600 \times 400$, respectively while minimum alkali spreading value, were recorded in R-3747 that was $360 \times 500$ Followed by R-3746 that was $365 \times 466$ respectively. All the varieties of aromatic short grain and medium slender rice genotypes differed non significantly regarding alkali spreading value. The amylose content was ranged from 18.94-26.06 per cent respectively. The maximum amylose content were obtained in Kalmunhi 26.06 per cent, followed by Kala Namak, 25.33 per cent respectively, while minimum amylose content, were recorded in R-2812 that was 18.94 per cent, followed by R-2809 that was 18.98 per cent respectively. The result indicate the variation observed softness characteristics of All the varieties of aromatic short grain and medium slender rice genotypes differed in softness which was less, medium and more softness. 


\section{Introduction}

Rice (Oryza sativa L.) is one of the most important staple foods in the world. About $90 \%$ of all rice grown in the world is produced and consumed in the Asian region where more than two billion people are getting $60-70 \%$ of their energy from rice. In the global scenario, the present population of 7.64 billion is expected to reach a figure of 9.77 billion by 2050. Rice is the world's second most important cereal crop after corn. Nearly 482 million metric tons of husked rice was produced in the last harvesting year worldwide. Traditionally, countries in Asia have the largest share in the world rice production. According to the most recent official data, with a production volume of over 210 million metric tons in 2017, China was the world's leading paddy rice producer, followed by India and India produce 99.18 million tons in 2017 and productivity is 2600 kilograms per hectare. Worldwide rice area is $161.1 \mathrm{~m}$ ha. Total global consumption of milled rice amounted to approximately 477.77 million metric tons in 2017 (Anonymous, 2018). Rice is grown in almost all the states of India with highest area in West Bengal followed by Andhra Pradesh and Bihar. Productivity of rice is highest in Punjab followed by Haryana and Tamilnadu. Uttar Pradesh occupies an area of 5.95 million hectare with an estimated annual production of 14.56 million tones. (Anonymous, 2016-17). The nutritional level of rice is high among cereals and other grains. The major part of rice kernel consists of carbohydrates in the form of starch $72-75 \%$. Rice grain quality is determined by its physical and chemical properties as head rice recovery, seed length, seed breadth, seed breadth ratio an alkali spreading value amylose content and softness.

\section{Materials and Methods}

The Laboratory experiment were conducted during 2016 and 2018, in Completely
Randomized Design with three replications on some aromatic short grain and medium slender aromatic rice genotypes at laboratory of department of Agricultural Biochemistry, department of Agronomy and Bio control lab of C.S. Azad University of Agriculture and Technology Kanpur, entitled "Physical and chemical studies of some Short grain and Medium slender aromatic rice (Oryza sativa L.)" The experiment was conducted under head rice recovery, seed length, seed breadth, seed breadth ratio the alkali spreading value and amylose content and softness. For the head rice recovery whole grains were collected from milled rice sample and then recorded weight of each variety/ strain was recorded separately and per cent HRR was calculated by

$\operatorname{HRR} \%=$

weight of whole grain of milled rice wt.of paddy x 100

Seed length and seed breadth of various rice varieties were determined by "Vernier Calliper's and measured in mm. Breadth of grain was measured by Dail Chackiness measuring machine. The L: B ratio of samples was determined on the basis of average length and width ratio of rice kernel. Kernel length and breadth measured by "Vernier Calliper's and the length of kernel divided by breadth. It indicates the length/breadth ratio (L/B ratio) and computed as follows:

Length Breadth ratio $=$ Kernel length $/$ Kernel breadth

The milled rice kernels were placed in $10 \mathrm{ml}$ 1.7 per cent $\mathrm{KOH}$ in shallow contain and arrange them so that they don't touch. Let it stand for 23 hours at $30^{\circ} \mathrm{C}$ and score for the alkali spreading value. The amylose content was determined by the method recommended by Juliano (1979). 


\section{Treatment varieties: $\mathbf{4 0}$}

\begin{tabular}{|c|c|c|}
\hline S.N. & TREATMANTS & VARIETIES \\
\hline 1 & V1 & R-3704 \\
\hline 2 & V2 & R-3715 \\
\hline 3 & V3 & R-3717 \\
\hline 4 & V4 & R-3719 \\
\hline 5 & V5 & R-3720 \\
\hline 6 & V6 & R-3721 \\
\hline 7 & V7 & R-3722 \\
\hline 8 & V8 & R-3724 \\
\hline 9 & V9 & R-3726 \\
\hline 10 & V10 & R-3728 \\
\hline 11 & V11 & R-3729 \\
\hline 12 & V12 & R-3730 \\
\hline 13 & V13 & R-3732 \\
\hline 14 & V14 & R-3734 \\
\hline 15 & V15 & R-3736 \\
\hline 16 & V16 & R-3737 \\
\hline 17 & V17 & R-3738 \\
\hline 18 & V18 & R-3743 \\
\hline 19 & V19 & R-3745 \\
\hline 20 & V20 & R-3746 \\
\hline 21 & V21 & R-3747 \\
\hline 22 & V22 & R-3748 \\
\hline 23 & V23 & $\mathrm{R}-2801$ \\
\hline 24 & V24 & R-2802 \\
\hline 25 & V25 & R-2803 \\
\hline 26 & V26 & R-2804 \\
\hline 27 & V27 & R-2805 \\
\hline 28 & V28 & R-2806 \\
\hline 29 & V29 & R-2808 \\
\hline 30 & V30 & R-2809 \\
\hline 31 & V31 & R-2812 \\
\hline 32 & V32 & R-2816 \\
\hline 33 & V33 & R-2818 \\
\hline 34 & V34 & R-2819 \\
\hline 35 & V35 & $\mathrm{R}-2821$ \\
\hline 36 & V36 & R-2824 \\
\hline 37 & V37 & P-1509 \\
\hline 38 & V38 & Pa-1121 \\
\hline 39 & V39 & Kalmuhin \\
\hline 40 & V40 & Kala Namak \\
\hline
\end{tabular}




\section{Results and Discussion}

Table 1 presented in the preceding experiments showed the head rice recovery, seed length, seed breadth and length breadth ratio. The head rice recovery ranged from 51.86-64.70 per cent and these values are closely related with the results reported by Ghosh and Chaudhary (1978), Verma and Srivastava (1993), Sarkar et al., (1994), Singh et al., (1997), Pandey et al., (1999), Khan et al., (2000), Singh et al., (2000) and Patindol and Wang (2002). Grain size and shape hardness, presence or absence of abdominal while, moisture content processing and type of mills employed have direct bearing on head rice recovery. The varieties of aromatic short grain and medium slender rice genotypes having white centre gives lower head rice yield but translucent grain gives high head rice grain. Hence, the varieties of aromatic short grain and medium slender rice genotypes were differed significantly (Rani et al., 2006).

The seed length varied from 4.96-7.26 mm respectively. Seed size is governed by its genetic potential. The present data on all the varieties of aromatic short grain and medium slender rice genotypes obtained was found to be similar to the value reported by Khan et al., (2000). The seed breadth varied from 1.63$1.95 \mathrm{~mm}$ respectively. Seed size is governed by its genetic potential. The present data on all the varieties of aromatic short grain and medium slender rice genotypes obtained was found to be similar to the value reported by Khan et al., (2000). The L/B ratio in the range of 4.96-7.26 mm, 1.63-1.95 mm and 1.70-3.70 $\mathrm{mm}$, respectively. It is governed by genetic potential. Highest length and kernel length and $\mathrm{L}$ : $\mathrm{B}$ ratio observed in R-2804 i.e., $3.70 \mathrm{~mm}$. followed by Kala Namak i.e., $3.68 \mathrm{~mm}$ and maximum breadth observed in $1.95 \mathrm{~mm}$ in R3746, followed by R-3724 i.e., $1.93 \mathrm{~mm}$. Similar observations have been also recorded by Panwar et al., (1991), Chaubey et al.,
(1988), Singh et al., (1997), Pandey et al., (1999), Khan et al., (2000), Singh et al., (2000), Sharma (2000), Sharma et al., (2005) and Husaini et al., (2009). Hence, varieties were differed significantly (Rani et al., 2006).

Table 2 presented in the preceding experiments showed the chemical composition of some important nutritional factors like Amylose content, alkali spreading value and softness of all the varieties of aromatic short grain and medium slender rice genotypes. The chemical parameters in the present investigation are discussed below under following underlines resulted as the amylose content was varied from 18.94-26.06 per cent in milled rice. Amylose content ranged from 18.94-26.06 per cent in various varieties of aromatic short grain and medium slender rice genotypes respectively. It is governed by genetic potential. The amylose content of various varieties of aromatic short grain and medium slender rice genotypes. The results have been supported by Kim et al., (1980), Chaubey et al., (1988), Panwar et al., (1991), Chikkalingaiah et al., (1997), Singh et al., (1997), Borua et al., (2003), Nayak et al., (2003), Patindol and Wang (2002), Zhou et al., (2002), Sood et al., (2006), Trivedi (200506), Bansal et al., (2006), Devi et al., (2008) and Husaini et al., (2009). The data showed tha Alkali Spreading Value varied from $360 \times 500-600 \times 466 \mathrm{ml}$ respectively. Maximum alkali spreading value was $600 \times 466 \mathrm{ml}$ in $\mathrm{R}$ 3738 , respectively. The variability lies among the varieties to assess the gelatinization temperature in various varieties of aromatic short grain and medium slender rice genotypes.. Our results are in agreement with Abidi et al., (1973). The result presented in table 2 indicate the variation observed appearance characteristics of All the varieties of aromatic short grain and medium slender rice genotypes differed in appearance which was less, medium and more softness. 
Table.1 Physical parameters

\begin{tabular}{|c|c|c|c|c|c|}
\hline \multirow[t]{2}{*}{ S.N. } & \multirow[t]{2}{*}{ Varieties } & \multirow{2}{*}{$\begin{array}{c}\text { Head } \\
\text { Recovery }\end{array}$} & \multicolumn{2}{|c|}{ Seed Size } & \multirow{2}{*}{$\begin{array}{c}\text { L/B } \\
\text { Ratio }\end{array}$} \\
\hline & & & $\begin{array}{c}\text { Length } \\
\text { (mm) }\end{array}$ & $\begin{array}{c}\text { Breadth } \\
(\mathbf{m m})\end{array}$ & \\
\hline 1 & R-3704 & 55.40 & 6.73 & 1.85 & 2.65 \\
\hline 2 & R-3715 & 57.47 & 4.96 & 1.90 & 2.99 \\
\hline 3 & R-3717 & 63.79 & 6.14 & 1.89 & 3.03 \\
\hline 4 & R-3719 & 64.70 & 5.60 & 1.86 & 2.71 \\
\hline 5 & R-3720 & 61.38 & 6.96 & 1.74 & 1.70 \\
\hline 6 & R-3721 & 56.97 & 6.46 & 1.83 & 1.95 \\
\hline 7 & R-3722 & 58.18 & 6.50 & 1.79 & 1.81 \\
\hline 8 & R-3724 & 57.85 & 6.16 & 1.73 & 3.47 \\
\hline 9 & R-3726 & 61.30 & 5.94 & 1.87 & 3.40 \\
\hline 10 & R-3728 & 57.76 & 7.24 & 1.81 & 2.80 \\
\hline 11 & R-3729 & 62.59 & 6.06 & 1.82 & 3.22 \\
\hline 12 & R-3730 & 55.83 & 5.36 & 1.82 & 3.26 \\
\hline 13 & R-3732 & 60.65 & 6.56 & 1.72 & 2.64 \\
\hline 14 & R-3734 & 54.51 & 6.94 & 1.93 & 2.25 \\
\hline 15 & R-3736 & 56.34 & 6.87 & 1.85 & 2.30 \\
\hline 16 & R-3737 & 57.05 & 6.33 & 1.71 & 1.79 \\
\hline 17 & R-3738 & 57.71 & 7.26 & 1.63 & 1.81 \\
\hline 18 & R-3743 & 59.67 & 6.00 & 1.92 & 1.91 \\
\hline 19 & R-3745 & 60.66 & 5.76 & 1.76 & 2.28 \\
\hline 20 & R-3746 & 59.01 & 6.10 & 1.95 & 2.90 \\
\hline 21 & R-3747 & 55.28 & 6.87 & 1.65 & 2.86 \\
\hline 22 & R-3748 & 56.50 & 6.23 & 1.68 & 2.88 \\
\hline 23 & R-2801 & 58.18 & 5.46 & 1.76 & 2.74 \\
\hline 24 & R-2802 & 57.34 & 6.69 & 1.73 & 2.94 \\
\hline 25 & R-2803 & 56.33 & 6.25 & 1.86 & 3.20 \\
\hline 26 & R-2804 & 56.76 & 6.36 & 1.88 & 3.70 \\
\hline 27 & R-2805 & 56.96 & 6.48 & 1.70 & 3.32 \\
\hline 28 & R-2806 & 56.56 & 5.97 & 1.71 & 2.94 \\
\hline 29 & R-2808 & 57.83 & 6.28 & 1.74 & 3.27 \\
\hline 30 & R-2809 & 59.35 & 6.91 & 1.72 & 2.81 \\
\hline 31 & R-2812 & 61.11 & 6.57 & 1.84 & 2.21 \\
\hline 32 & $\mathrm{R}-2816$ & 61.37 & 6.45 & 1.76 & 2.09 \\
\hline 33 & R-2818 & 59.71 & 7.20 & 1.75 & 2.87 \\
\hline 34 & $\mathrm{R}-2819$ & 58.65 & 6.56 & 1.85 & 1.82 \\
\hline 35 & R-2821 & 58.36 & 6.66 & 1.84 & 3.42 \\
\hline 36 & R-2824 & 59.59 & 6.10 & 1.89 & 3.25 \\
\hline 37 & P-1509 & 59.76 & 6.86 & 1.72 & 2.85 \\
\hline 38 & $\mathrm{~Pa}-1121$ & 56.70 & 6.46 & 1.72 & 1.95 \\
\hline 39 & Kalmunhi & 51.86 & 6.33 & 1.68 & 3.41 \\
\hline 40 & Kala Namak & 55.56 & 6.08 & 1.90 & 3.67 \\
\hline 41 & CD at $5 \%$ & 5.05 & 0.97 & 0.06 & 1.12 \\
\hline
\end{tabular}


Table.2 Nutritional parameters

\begin{tabular}{|c|c|c|c|c|}
\hline S.N. & Varieties & Amylose Content & Alkali Spreading Value & Softness \\
\hline 1 & $\mathrm{R}-3704$ & 21.46 & $580 \times 481$ & More \\
\hline 2 & $\mathrm{R}-3715$ & 24.54 & $500 \times 400$ & Medium \\
\hline 3 & R-3717 & 19.79 & $450 \times 480$ & Less \\
\hline 4 & R-3719 & 21.50 & $410 \times 400$ & More \\
\hline 5 & R-3720 & 21.76 & $500 \times 440$ & Medium \\
\hline 6 & R-3721 & 23.13 & $525 \times 500$ & More \\
\hline 7 & $\mathrm{R}-3722$ & 21.82 & $600 \times 400$ & Less \\
\hline 8 & R-3724 & 19.62 & $510 \times 425$ & Medium \\
\hline 9 & R-3726 & 23.58 & $500 \times 435$ & Less \\
\hline 10 & R-3728 & 20.19 & $450 \times 350$ & More \\
\hline 11 & R-3729 & 24.51 & $450 \times 550$ & Less \\
\hline 12 & $\mathrm{R}-3730$ & 24.64 & $455 \times 450$ & Medium \\
\hline 13 & R-3732 & 19.68 & $550 \times 400$ & Less \\
\hline 14 & R-3734 & 24.07 & $500 \times 400$ & More \\
\hline 15 & R-3736 & 24.04 & $500 \times 300$ & Less \\
\hline 16 & $\mathrm{R}-3737$ & 19.81 & $400 \times 500$ & Medium \\
\hline 17 & $\mathrm{R}-3738$ & 23.33 & $600 \times 466$ & More \\
\hline 18 & $\mathrm{R}-3743$ & 23.16 & $566 \times 455$ & Less \\
\hline 19 & R-3745 & 19.16 & $500 \times 488$ & Medium \\
\hline 20 & R-3746 & 24.12 & $365 \times 466$ & Less \\
\hline 21 & R-3747 & 24.70 & $360 \times 500$ & More \\
\hline 22 & R-3748 & 24.12 & $540 \times 300$ & Less \\
\hline 23 & $\mathrm{R}-2801$ & 23.36 & $450 \times 400$ & Medium \\
\hline 24 & $\mathrm{R}-2802$ & 24.63 & $600 \times 400$ & Less \\
\hline 25 & $\mathrm{R}-2803$ & 24.07 & $450 \times 450$ & Less \\
\hline 26 & $\mathrm{R}-2804$ & 24.46 & $360 \times 450$ & Less \\
\hline 27 & $\mathrm{R}-2805$ & 24.29 & $450 \times 450$ & More \\
\hline 28 & R-2806 & 23.22 & $450 \times 450$ & Less \\
\hline 29 & $\mathrm{R}-2808$ & 23.60 & $540 \times 350$ & Medium \\
\hline 30 & R-2809 & 18.98 & $450 \times 335$ & Less \\
\hline 31 & $\mathrm{R}-2812$ & 18.94 & $455 \times 450$ & Medium \\
\hline 32 & $\mathrm{R}-2816$ & 20.66 & $380 \times 425$ & Less \\
\hline 33 & $\mathrm{R}-2818$ & 23.76 & $480 \times 400$ & More \\
\hline 34 & $\mathrm{R}-2819$ & 24.49 & $500 \times 500$ & Less \\
\hline 35 & R-2821 & 24.63 & $555 \times 440$ & Medium \\
\hline 36 & $\mathrm{R}-2824$ & 23.93 & $400 \times 460$ & Less \\
\hline 37 & P-1509 & 19.37 & $380 \times 470$ & More \\
\hline 38 & Pa-1121 & 22.97 & $480 \times 540$ & Less \\
\hline 39 & Kalmunhi & 26.06 & $500 \times 520$ & More \\
\hline 40 & Kala Namak & 25.33 & $510 \times 530$ & More \\
\hline 41 & CD at $5 \%$ & 1.94 & N/A & N/A \\
\hline
\end{tabular}


The present experiments concluded that the entitled "Physical and chemical studies of some Short grain and Medium slender aromatic rice (Oryza sativa L.)" explained as the head rice recovery ranged from 51.8664.70 per cent, Grain size and shape hardness, presence or absence of abdominal while, moisture content processing and type of mills employed have direct bearing on head rice recovery. The seed length varied from 4.96$7.26 \mathrm{~mm}$ respectively. Seed size is governed by its genetic potential. The seed breadth varied from 1.63-1.95 mm respectively. Seed size is governed by its genetic potential. The $\mathrm{L} / \mathrm{B}$ ratio range of 4.96-7.26 mm, 1.63-1.95 $\mathrm{mm}$ and $1.70-3.70 \mathrm{~mm}$, respectively. It is governed by genetic potential. Highest length and kernel length and L: B ratio observed in R-2804 i.e., $3.70 \mathrm{~mm}$. followed by Kala Namak i.e., $3.68 \mathrm{~mm}$ and maximum breadth observed in $1.95 \mathrm{~mm}$ in R-3746, followed by R-3724 i.e., $1.93 \mathrm{~mm}$.

The chemical parameters in the present investigation are discussed below under following underlines resulted as the amylose content was varied from 18.94-26.06 per cent in milled rice. Amylose content ranged from 18.94-26.06 per cent in various varieties of aromatic short grain and medium slender rice genotypes respectively. It is governed by genetic potential. The data showed that Alkali Spreading Value varied from 360×500$600 \times 466 \mathrm{ml}$ respectively. Maximum alkali spreading value was $600 \times 466 \mathrm{ml}$ in $\mathrm{R}-3738$, respectively. All the varieties of aromatic short grain and medium slender rice genotypes differed in appearance which was less, medium and more softness.

\section{References}

Abidi, A. B., Mehrotra, O.N. and Srivastva, G.P. (1973). Quality characteristics of rice grain of some new strains of Uttar Pradesh. Ind. J. Agric. Chem., 6: 73-78.
Anonymous-Agri. Statista- the portal for statistics. Rice statistics and facts about rice. (2018)

Anonymous-Annual Report UPCAR- 201617

Borua. I., Ahmed. S.A., Sarkar, C.R. and Das, D. (2003). Biochemical evaluation of scented rice of north east India. National Symposium on "Biochemical approaches of utilization and exploitation of commercially important plant”, Jorhat India, 12-14 Nov.

Chaubey, P. K., Nanda, B. B., Richariya, A. K. (1988). Quality attributing characters of scented and non-scented rice. Oryza, 25: 325-328.

Chikkalingaiah, G. E., Ramesh, S. and Mohan, R.A. (1997). Evaluation of some selections of aromatic rices for quality traits. Mysore J. Agric. Sci., 31: 201-204.

Devi, T.P., Durai, A.A., Singh, S., Gupta, S., Mitra, A., Sharma, B. K. and Das, A. (2008). Preliminary studies on physical and nutritional qualities of some indigenous and important rice cultivars of north-eastern hill region of India. Journal of Food Quality, 31 (6): 686700.

Ghosh, A. K. and Chaudhury, D. (1978). Evaluation of agronomic and physiochemical characteristics of fine and scented rice varieties. Ind. J. Agric. Sci., 48: 575-578.

Husaini, A.M., Parray, A,G. and Sanghera, G.S. (2009). Performance of elite basmati rice varieties of subtropical India under temperate valley condition of Kashmir. International Rice Research Notes: 0117-4185

Juliano, B. O. (1979). Amylose analysis in rice - A review. In: Proc. Workshop on chemical aspects of rice grain quality. IRRI, Los Banos, Philippines: 251-260.

Khan, M.G., Akhter, M. And Sabar, M. (2000). Basmati 2000 an extra long 
grained aromatic rice variety. International Rice Research Notes, 28(1): 33-35

Kim, Y. B., Lee, B. Y., Park, N. K. and Han, P. J. (1980). Studies on simplified rice storage for farmer. Research Report of Office Rural Development Agriculture Engineering. Farm Products Utilization and Farm Management, 22: 18-24.

Nayak, A. R., Chaudhary, D. and Reddy, J. N. (2003). Inter relationship among quality characters in scented rice. Ind. J. Agric. Res., 37 (2): 124-127.

Pandey, N., Sarawgi, A. K., Rastogi, N. K. and Tripathi, R.S. (1999). Effect of FYM and chemical fertilizer on grain yield and quality of scented rice (Oryza sativa) varieties. Indian J. Agric. Sci., 69 (99): 621-623.

Pandey, N., Sarawgi, A. K., Rastogi, N. K. and Tripathi, R.S. (2002). Effect of FYM and chemical fertilizer on grain yield and quality of scented rice (Oryza sativa) varieties. Indian J. Agric. Sci., 69 (99): 621-623.

Pantidol, J. And Wang, Y.J. (2002). Fine structure of starches from long grain rice cultivars with different functionality. Cereal Chem, 79(3), 465469.

Panwar, D.V.S., Gupta, K. R., Battan, K. R., and Singh, A. (1991). HKR 228, a semidward aromatic rice strain for Haryana, India. Intl. Rice. Res. Newsl. 16: 16-17

Rani, S.N. (2006). Quality consideration in developing rice hybrids. Doctrate of rice research, Hyderabad. PP. 180-187.

Sarkar, R. K., Nanda, B. B., Dash, A. B. and Lodh, S. B. (1994). Grain characteristics and cooking quality of aromatic and non- aromatic long slender varieties of rice (Oryza sativa L.) Ind. $J$. Agric. Sci., 20 (2): 132-142.

Sharma, N., Mangai, G. S., Singh, N. And Bharoj, T.S. (2005). Identification of donor quality traits in fine grain aromatic rice. Indian Journal of Agricultural Sciences. 75: 831-83.

Singh, R. and Srivastava, V. K. (1997). Report on Basmati and Scented Fine grained types at Varanasi Centre., B. H. U., Varnasi, U.P. p. 30.

Singh, R.K., Singh, U.S., Khus G.S., Rohilla, R., Singh, J.P. and Shekhar, K.S. (2000). Small and medium grained aromatic rice of India. In Aromatic Rice (Singh R.K., Singh U.S. and Khus G.S. editors) Oxford \& IBP Publication.PP.155-178.

Sood, D. R., Singh, A.P. and Shilpa (2006). Changes in cooking behavior of basmati and non-basmati rice genotypes during storage. J. Dairying, Food and Home Sci., 25 (2): 25-38.

Trivedi, V. (2006). Biochemical studied of scented rice varieties (Oryza sativa L.) M.Sc.(Ag) Thesis, N.D. University of Agriculture \& Technology, Kumarganj. (Faizabad).

Verma, M. L. and Srivastava, G. P. (1993). Grain quality characteristics of some aromatic slender grained rice varieties. Indian J. Agric. Chem., 26(2): 101-105.

Zhout, Z., Robards, K., Helliwell, S., \& Blanchard, C. (2002). Ageing of stored rice: changes in chemical and physical attributes. Journal of Cereal Science, $35,65-78$.

\section{How to cite this article:}

Dharmadew Chauhan, Mukesh Mohan, Pawan Kumar Goutam, Dipak Kumar and Ajay Sonkar. 2019. Physical and Chemical Studies of Some Short Grain and Medium Slender Aromatic Rice (Oryza sativa L.). Int.J.Curr.Microbiol.App.Sci. 8(01): 2602-2609.

doi: https://doi.org/10.20546/ijcmas.2019.801.273 